
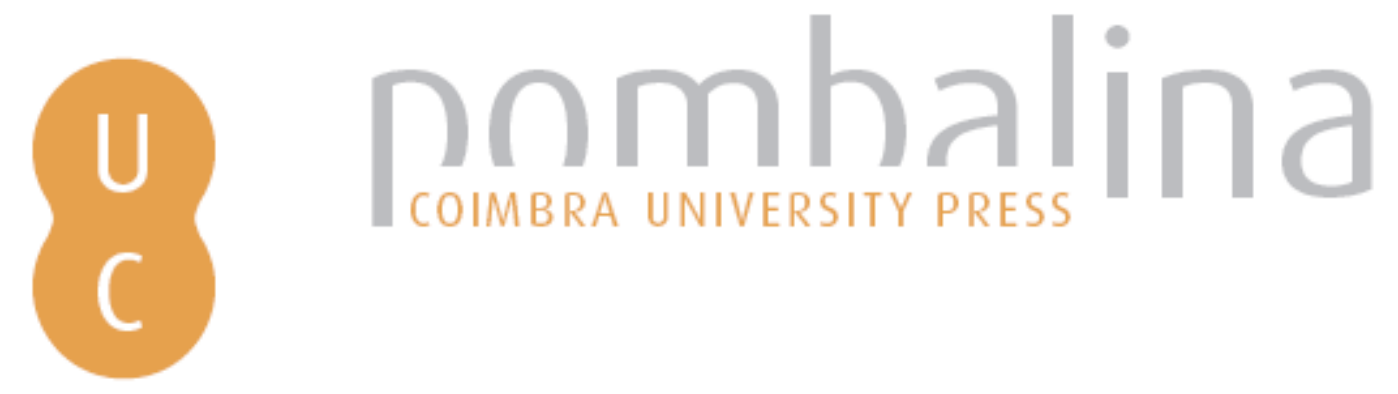

\title{
A paisagem como elemento de sustentabilidade nos territórios de fronteira: 0 exemplo do município do Sabugal
}
Autor(es):
Nunes, Adélia; Almeida, António Campar de
Publicado por: Imprensa da Universidade de Coimbra
URL
persistente:
URI:http://hdl.handle.net/10316.2/43481
DOI:
DOI:https://doi.org/10.14195/978-989-26-1343-7_11
Accessed : $\quad$ 26-Apr-2023 14:31:52

A navegação consulta e descarregamento dos títulos inseridos nas Bibliotecas Digitais UC Digitalis, UC Pombalina e UC Impactum, pressupõem a aceitação plena e sem reservas dos Termos e Condições de Uso destas Bibliotecas Digitais, disponíveis em https://digitalis.uc.pt/pt-pt/termos.

Conforme exposto nos referidos Termos e Condições de Uso, o descarregamento de títulos de acesso restrito requer uma licença válida de autorização devendo o utilizador aceder ao(s) documento(s) a partir de um endereço de IP da instituição detentora da supramencionada licença.

Ao utilizador é apenas permitido o descarregamento para uso pessoal, pelo que o emprego do(s) título(s) descarregado(s) para outro fim, designadamente comercial, carece de autorização do respetivo autor ou editor da obra.

Na medida em que todas as obras da UC Digitalis se encontram protegidas pelo Código do Direito de Autor e Direitos Conexos e demais legislação aplicável, toda a cópia, parcial ou total, deste documento, nos casos em que é legalmente admitida, deverá conter ou fazer-se acompanhar por este aviso.

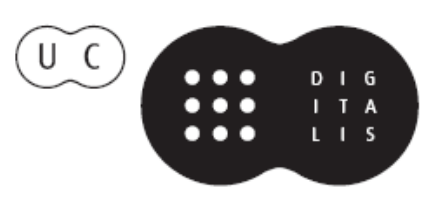




\section{FERNANDA CRAVIDÃO}

\section{IÚCIO CUNHA}

PAULA SANTANA

\section{NORBERTOSANTOS}

(ORG.)

\section{ESPAÇOS E TEMPOS EM GEOGRAFIA}

HOMENAGEM A ANTÓNIO GAMA

IMPRENISA DÁ UNIVERSIDADE DE COIMBRA COIMBRA UNIVERSITY PRESS

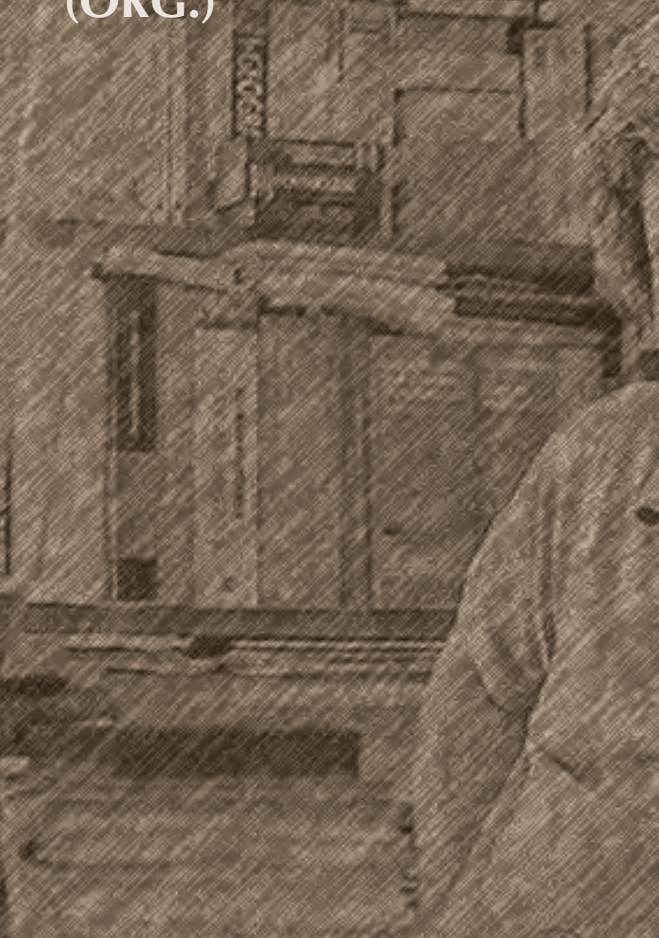




\title{
A paisagem COMO elemento DE SUSTENTABILIDADE NOS TERRITÓRIOS DE FRONTEIRA. O EXEMPLO DO MUNICÍPIO DO SABUGAL
}

\author{
Adélia Nunes/adelia.nunes@fl.uc.pt \\ Departamento de Geografia e Turismo, CEGOT, FLUC \\ António Campar de Almeida/campar@fl.uc.pt \\ Departamento de Geografia e Turismo, CEGOT, FLUC
}

\section{Introdução}

A paisagem é, cada vez mais, reconhecida como uma parte fundamental do património natural, cultural e científico, base da identidade territorial (DGT, 2015). Por conseguinte, a sua conservação, recuperação, valorização e gestão é fundamental numa política de ordenamento do território e num contexto de sustentabilidade. Wu (2013) define sustentabilidade da paisagem como a capacidade de uma paisagem em fornecer, de forma consistente e a longo prazo, serviços de ecossistemas específicos dessa paisagem, essenciais para manter e melhorar o bem-estar humano. $\mathrm{O}$ mesmo autor acrescenta que a sustentabilidade se centra, ainda, na análise de como manter e melhorar a relação dinâmica entre as funçóes e os serviços de paisagem e o bem-estar humano, em contextos de mudança social, económica e ambiental.

O funcionamento adequado e sustentado das paisagens fornece uma ampla gama de serviços que são essenciais para a sociedade, oferecendo diversos 
benefícios que são conhecidos como "serviços dos ecossistemas" (Groot et al., 2002; MEA, 2005; Pereira et al., 2009; Groot et al., 2010). Groot et al. (2002) definem funçóes da paisagem (ou dos ecossistemas) como "a capacidade dos ecossistemas em fornecer bens e serviços que satisfaçam, direta ou indiretamente, as necessidades humanas". No glossário de termos apresentado pela iniciativa TEEB (The Economics of Ecosystems and Biodiversity, 2010) são descritas como funções da paisagem "as interações entre a estrutura dos ecossistemas (a forma como se organizam os ecossistemas) e os processos dos ecossistemas, que lhe conferem capacidade para gerar serviços e bens".

De facto, a sociedade atual depende dos serviços que os ecossistemas the prestam, cuja valoração se baseia nos efeitos que cada serviço tem ao nível do bem-estar da sociedade (Almeida, 2013). No entanto, a capacidade das paisagens em fornecer serviços é suscetível de mudar ao longo do tempo (Holland et al., 2011; Lautenbach et al., 2011; Jiang et al., 2013; Dallimer et al., 2015; Burgi et al., 2015), por efeito de fatores diretos (como por exemplo as mudanças no uso do solo e coberto vegetal, introdução ou remoção de determinadas espécies vegetais, adaptação e uso de tecnologias, mudanças climáticas) e indiretos (demográficos, económicos, sociopolíticos, culturais). As mudanças no uso do solo e cobertura vegetal, graças ao seu papel primordial, desencadeiam importantes alteraçóes nas funçóes das paisagens e na quantidade e qualidade dos serviços que os ecossistemas podem fornecer (Zhao et al., 2006; Tianhong et al., 2010; Dearing et al., 2012; Sil, 2014; Burgi et al., 2015).

O município do Sabugal, devido à localização fronteiriça, excêntrica e marginal, no contexto nacional e ibérico, evoca, na atualidade, a par de vastos territórios do país com idêntico posicionamento, a imagem de uma área periférica, isolada, pouco acessível, pobre, ou seja, o Interior na plenitude do significado geográfico, económico, social e cultural (Nunes e Jacinto, 2011). De facto, a desestruturação do sistema tradicional de exploração da terra, assente na trilogia agro-silvo-pastoril, com o consequente abandono de campos de cultivo, de áreas de floresta e da atividade pastoril tiveram reflexos na paisagem e nas respetivas funçóes e serviços por elas prestados/fornecidos. 
Com o presente trabalho pretende-se: i) analisar as mudanças ocorridas nos usos tradicionais do território, num passado recente, e identificar os respetivos impactes nos serviços dos ecossistemas; ii) identificar e discutir os principais serviços potencialmente prestados pelas unidades de paisagem identificadas no município do Sabugal; iii) refletir sobre a importância/necessidade de integrar a sustentabilidade da paisagem nos processos de planeamento e tomada de decisão, num processo estratégico mais alargado de valorização do espaço rural.

\section{Dos serviços dos ecossistemas à sustentabilidade da paisagem}

É vasto o conjunto de serviços de ecossistemas referidos na literatura (ex. Costanza et al., 1997; Groot et al., 2002; Millennium Ecosystem Assessment, MEA, 2005; TEEB, 2010; Groot et al., 2010), utilizando, por vezes, diferentes esquemas de classificação. Da tipologia proposta pelo MEA para a descrição, classificação e valorizaçáo de um conjunto de serviços dos ecossistemas, emergem 4 categorias principais (Figura 1):

- Serviços de produçáo (também designados de aprovisionamento): englobam todos os produtos que as pessoas obtêm dos ecossistemas tais como alimentos, combustível, fibras, água potável, recursos genéticos e medicamentos.

- Serviços de regulaçáo: refere-se à capacidade que um ecossistema natural ou semi-natural tem na regulação de processos e sistemas essenciais, de suporte à vida ecológica através de ciclos biogeoquímicos e outros processos da biosfera; constituem benefícios "intangíveis" (em geral, sem valor de mercado). Exemplos: regulação climática, manutenção da qualidade do ar, regulação hidrológica, controlo da erosão, purificação da água e reciclagem de resíduos, regulação das doenças humanas, controlo biológico (pragas das culturas e doenças dos animais), polinização e mitigação dos efeitos de tempestades e outras catástrofes naturais. 
- Serviços culturais (também designados de informação): benefícios diretos não materiais, ainda que por vezes com valor de mercado, obtidos dos ecossistemas. Incluem o turismo, lazer e recreio, benefícios estéticos, bem-estar físico e enriquecimento espiritual, sentido de pertença, experiências educacionais e patrimoniais.

- Serviços de suporte: A maior parte das atividades humanas (ex. cultivo, habitação, transporte) requerem espaço e um substrato adequado. Dependendo do tipo de atividade, diferentes condiçôes ambientais e de usos do solo são requeridos (ex. estabilidade e fertilidade do solo, qualidade do ar e da água, topografia, clima, geologia, etc.).

De acordo com MEA (2005) existe uma interação dinâmica entre as pessoas e os ecossistemas. Assim, as alteraçóes que afetem os serviços dos ecossistemas têm efeitos no bem-estar humano através de impactes que promovem ao nível da segurança, recursos materiais básicos para uma vida com qualidade, saúde e relaçôes sociais e culturais (Figura 1). Estes componentes do bem-estar humano são, por seu turno, influenciados e têm influência na liberdade de escolha de cada indivíduo. Por sua vez, as componentes do bem-estar, vividas e percebidas pelas pessoas, são dependentes e refletem a geografia local, a cultura e as circunstâncias ecológicas.

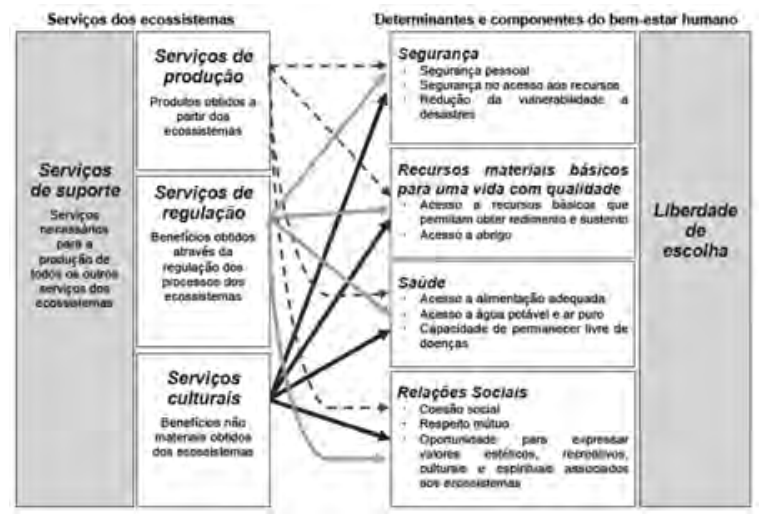

Figura 1

Os serviços dos ecossistemas e a sua relação com o bem-estar humano.

(Adaptado de Pereira et al., 2009.) 
É nesta perspetiva que emerge o conceito de sustentabilidade da paisagem como "a capacidade de uma paisagem para manter a sua estrutura básica e fornecer serviços de ecossistemas num mundo em mudança ambiental, económica e social" (Wu, 2012). De acordo com Musacchio (2009), uma paisagem sustentável representa o estado dinâmico do sistema, com múltiplas trajetórias e resultados, encarna multifuncionalidade, fornece serviços dos ecossistemas e é resiliente e adaptável". A sustentabilidade da paisagem inclui, assim, seis dimensôes: o ambiente, a economia, a equidade, a estética, a experiência e a ética (os seis Es). Para além das 3 dimensóes associadas, tradicionalmente, ao conceito de desenvolvimento sustentável, assente na valorizaçáo do capital social, económico e ambiental, o conceito de sustentabilidade das paisagens agrega outras dimensóes que se associam à estética, ética, experiência e equidade (Figura 2).

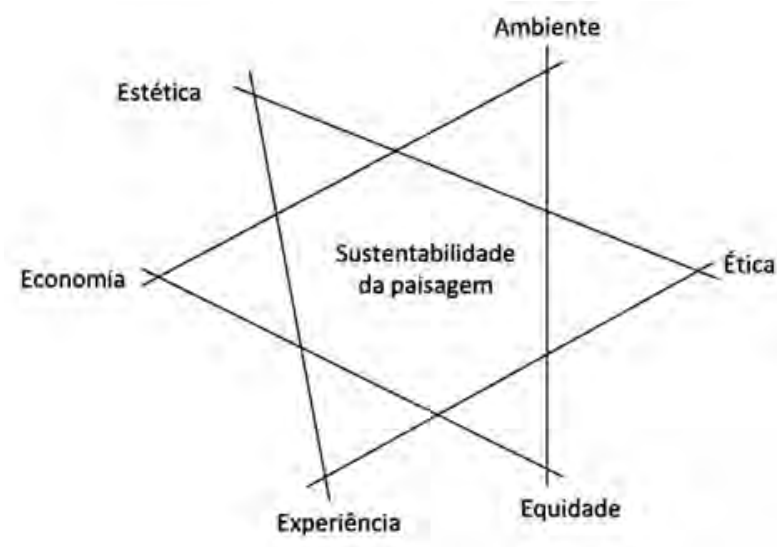

Figura 2

Elementos que integram a sustentabilidade da paisagem, de acordo com Musacchio (2009)

Cumming et al. (2012) referem que a sustentabilidade da paisagem pode ser vista de duas formas: (1) o grau em que os padrôes e processos que caraterizam a paisagem vão persistir indefinidamente no futuro; e (2) como é que as caraterísticas das paisagens afetam a sustentabilidade de outros elementos que são importantes para as pessoas (como os serviços de ecossistemas) ou para os 
outros organismos (como habitat, alimentos, companheiros). A segunda perspetiva é fortemente dependente da primeira.

No âmbito da sustentabilidade da paisagem, a paisagem é associada a um sistema socioambiental, espacialmente heterogéneo e com um foco na interação dos serviços dos ecossistemas e humanos.

\section{A desestruturaçáo do sistema produtivo tradicional e impactes nas funçóes e serviços dos ecossistemas/paisagem}

Fatores naturais, socioeconómicos e político-estruturais contribuiram para a desestruturação do sistema produtivo tradicional, cujos reflexos se fizeram sentir no abandono e subutilização do espaço agrícola e florestal. À pobreza dos solos em nutrientes e às condicionantes do clima, associaram-se causas de natureza socioeconómica, entre as quais se destacam a estrutura fundiária de pequenas exploraçóes fortemente compartimentadas, a deficiente qualificação dos recursos humanos, a incapacidade em atrair investimento e agentes de mudança, para além dos problemas de acessibilidade e do respetivo afastamento em relação aos grandes centros de decisão. A conjugação destes fatores propiciou o desmoronamento dos sistemas tradicionais de produção, confrontados com a incapacidade de se adaptarem às novas regras estabelecidas pelos mercados, no pós segunda Guerra Mundial. A sua marginalização em relação aos centros de decisão e consumo viria a provocar mudanças muito expressivas no uso do solo e na cobertura vegetal.

Todavia, a debandada da população do espaço rural, em particular durante e após os anos 60, devido às migraçóes internas e internacionais, terá sido o principal impulsionador das alteraçóes que ocorreram no município do Sabugal. Com a enorme saída de gente (cerca de 70\%, se compararmos os valores relativos à população residente constante nos recenseamentos da população de 1950 e 2011), desencadearam-se profundas alteraçóes na dinâmica populacional e na distribuição por setores de atividade, as quais se revelaram determinantes na forma e na intensidade de aproveitamento do solo. Com o ininterrupto 
despovoamento, perpetuado até à atualidade, geraram-se alteraçóes na estrutura demográfica, atualmente pautada por um exacerbado envelhecimento da população, em geral, e dos produtores agrícolas, em particular, e operou-se um desmantelamento da estrutura produtiva, antes baseada na necessidade de grande quantidade de mão de obra. Como corolário destas alteraçôes demográficas, económicas e estruturais verificou-se um abandono maciço das atividades agrícolas tradicionais, o que, aliás, é regra um pouco por todo o interior Centro e Norte, e mesmo Sul, de Portugal.

$\mathrm{Na}$ figura 3 sistematizam-se as principais alteraçóes resultantes da desestruturação do sistema produtivo tradicional, assente na trilogia agro-silvo-pastoril, cujos reflexos se fizeram sentir, de forma significativa na estrutura e composiçáo da paisagem e nas respetivas funçóes e serviços que, até então, predominavam (Nunes, 2007; Nunes, 2016).

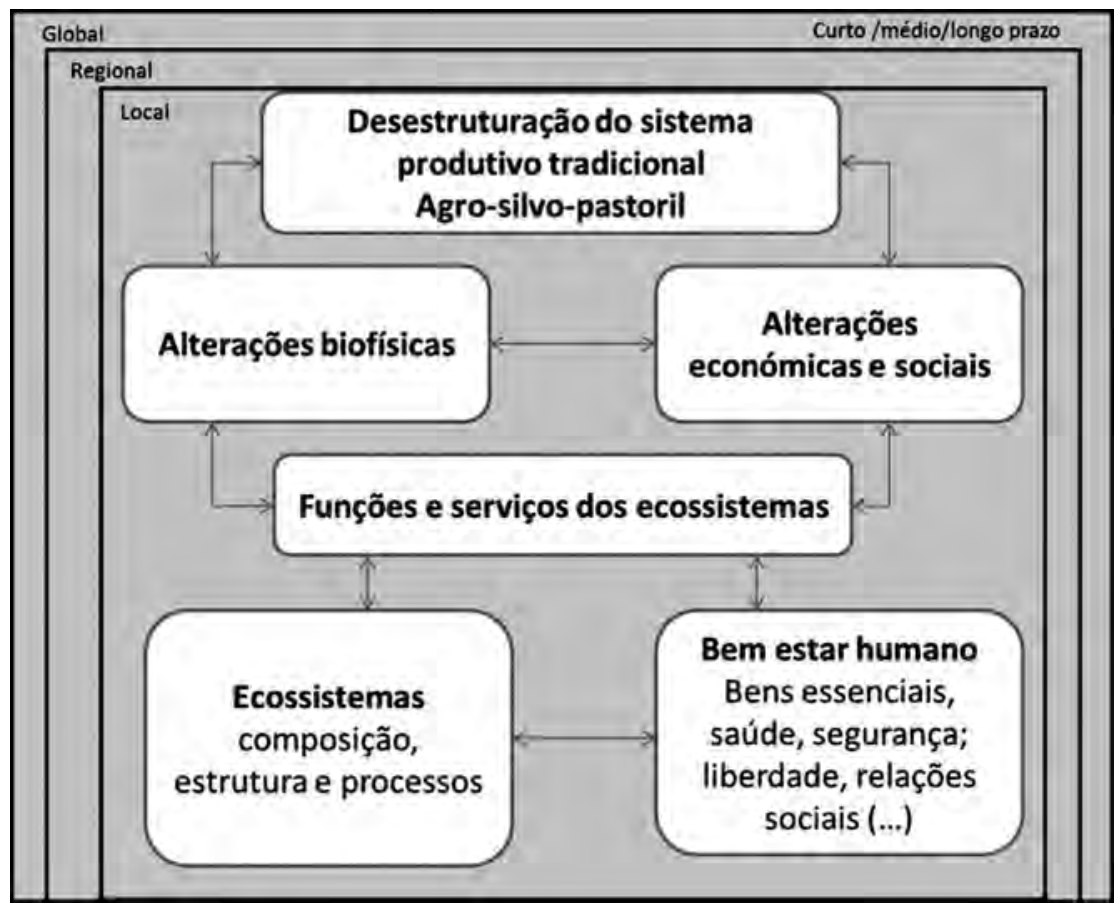

Figura 3

Desestruturação do sistema produtivo tradicional e impactes nas funçôes e serviços dos ecossistemas 
Com efeito, a função de produçấo, dominante durante vários decénios, tem vindo a degradar-se de forma significativa, como resultado do abandono das atividades tradicionais existentes naquele território, tanto em termos de culturas como criação de gado, o que resulta numa perda de bens e produtos (ex. cereais, batata, castanha, leite, lá, etc.). Também a nível florestal se verifica uma redução na produção de madeira, sobretudo pelo desaparecimento dos pinhais e da exploração de resina, assim como de lenha e cama para os animais. O processo de eletrificação e de acesso a combustíveis fósseis terá contribuído decisivamente para a desvalorização da produção de lenha enquanto recurso, a que se juntou a ocorrência recorrente de incêndios florestais, devido à acumulação de biocombustível.

No que se refere aos recursos biogenéticos, de igual modo têm vindo a assinalar um processo de degradação, sendo mesmo de destacar a extinção de algumas espécies animais, referidas, por exemplo, no Dicionário Geográfico de 1758 , como o veado ou o corso. O lobo e o lince encontram-se classificados como espécies fortemente ameaçadas, ou até mesmo em vias de extinçáo, muito por causa da ação antrópica direta, ex. a caça, mas também porque a fonte de alimento, o coelho e o gado miúdo sofreram um processo de regressão. Com o, quase, desaparecimento dos campos de cultivo, também os coelhos, as perdizes e alguns roedores foram afetados pela falta de alimento, a que se juntou a recorrente destruição dos respetivos habitats pela passagem frequente de incêndios florestais.

No que concerne aos serviços de regulação pode afirmar-se que, com o abandono de terras e a reflorestação (espontânea ou introduzida), assim como com a substituição da cultura de cereais por pastagens, se verifica uma notável redução das contribuiçóes de sedimentos, desde as vertentes até aos leitos fluviais, e assim uma regulaçáo de forma mais eficaz dos processos erosivos. Com efeito, durante o sistema tradicional, a agricultura cerealista ter-se-á convertido numa importante fonte de sedimentos para os cursos de água e fundos de vertentes, afetando em especial as vertentes de maior declive e os solos com deficientes estruturas de conservação (Nunes, 2008; García-Ruíz, 2010). 
Relativamente à regulação da qualidade do ar, do clima local/regional e dos recursos hídricos, as incertezas são maiores e necessitam de estudos específicos. Pode, no entanto, afirmar-se, no que toca à regulação dos recursos hídricos, que o abandono de vastas áreas, a par de um incremento nas áreas de floresta e de comunidades arbustivas, revela efeitos sobre a disponibilidade de recursos hídricos (Gallart \& Llorens, 2001; Beguería et al., 2003; Barbancho \& Tejeda, 2006; Nunes, 2008). São múltiplas as investigaçóes a concluir que a presença de densas comunidades arbustivas e arbóreas, apesar de favorecer a infiltração, limita o escoamento superficial e aumenta as perdas de água por interceção e evapotranspiração (Bosch \& Hewlett,1982; Belmonte Serrato et al., 1999; VanShaar et al., 2002). Um aspeto positivo, relacionado com o aumento no coberto vegetal, prende-se com o efeito regulador em situação de cheia.

Das funções reguladoras, além da já referida, uma das mais afetadas, pela negativa, prende-se com a forte incidência de incêndios. Tradicionalmente, a maior parte da biomassa produzida nas florestas era recolhida pela população e utilizada como fonte de combustível ou na cama dos animais. Por outro lado, nos pinhais recolhia-se a resina e a manta morta. A substituição da lenha por outras fontes de energia (gás, eletricidade...) quebrou este balanço "natural” e levou à acumulação de grandes quantidades de biomassa combustível. Também, a recolonização dos antigos campos de cultivo, com densas comunidades arbustivas e arbóreas, e sem qualquer tipo de gestão antrópica, favorecem a continuidade horizontal e vertical dos combustíveis, o que faz com que, nas épocas mais críticas em termos de evapotranspiração, devido à simultaneidade de temperaturas elevadas e escassez de precipitação, a propagação das chamas seja facilitada, explicando, em parte, este incremento na magnitude e frequência dos incêndios (Moreira et al., 2011; Nunes et al., 2013).

Com a recorrência de incêndios e a prevalência de comunidades arbustivas monoespecíficas, principalmente de Cytisus multiflorus (Nunes, 2008), não temos dúvidas que os processos de polinização e as funçóes de habitat têm sido fortemente penalizadas e sofreram um processo de degradação nas últimas décadas. Contudo, a recolonização dos antigos campos de cultivo com densas comunidades arbustivas e arbóreas detém um efeito benéfico na retenção 
de nutrientes e na fertilidade dos solos (função de suporte), pois as maiores quantidades de biomassa fornecidas por estas comunidades, promovem a melhoria da estrutura dos solos, favorecem a formação de agregados, contribuem para a diminuição da densidade e para uma maior porosidade, nos primeiros centímetros do solo, ao mesmo tempo que incrementam o respetivo teor de matéria orgânica e macronutrientes principais, como por exemplo o potássio assimilável (Pardini et al., 2002, Nunes et al., 2012).

Este incremento, tanto na biomassa das plantas como no carbono dos solos, pode ter um efeito particularmente benéfico no sequestro de carbono, o qual se refere à captura e remoção de $\mathrm{CO}_{2}$ da atmosfera convertido em carbono e armazenado na biomassa das plantas ao longo do tempo. Pinheiro et al. (2014), quando estudaram a relaçáo entre as transformaçóes na paisagem e a fixação de carbono numa freguesia de Bragança, entre 1958 e 2006 (cujas características biogeográficas não diferem significativamente da área de estudo), observaram um aumento do carbono fixado na paisagem de 4,9 t C/ha para 18,0 t C/ha, devido à expansão das áreas de floresta, à redução de áreas agrícolas e de matos e ao uso de menor biomassa por unidade de referência.

\section{O Sabugal e a(s) sua(s) paisagem(ns)}

O conceito de unidade de paisagem assenta no pressuposto da existência de elementos nucleares que, combinados entre si, conferem um determinado arranjo ou padrão espacial específico ao qual está associado um determinado carácter e escala de abordagem (Cancela d'Abreu et al., 2004). É também uma fração combinatória das condiçôes edafoclimáticas, coberto vegetal/uso do solo, povoamento humano e morfologia do terreno a uma determinada escala (idem, ibidem). Para Portugal, as grandes unidades de paisagem, definidas à escala 1:250.000, resultam dos estudos promovidos pela Direcção-Geral do Ordenamento do Território e Desenvolvimento Urbano (DGOTDU), sob a coordenaçấo de Cancela d'Abreu et al. (2004). A complexidade interna das unidades de paisagem depende, efetivamente, da escala de abordagem. 
Integrado na Paisagem da Beira Interior (G), o município do Sabugal abrange a parte meridional do Planalto da Beira Transmontana (unidade de paisagem 47B), sendo ainda de destacar a inserção de pequenas áreas em outras unidades: serra da Malcata (50), Vale do Côa (48) e Cova da Beira ${ }^{1}$ (49) (Figura 4).

\section{O planalto da Beira Transmontana}

O Planalto da Beira Transmontana constitui a mais importante unidade de paisagem no município do Sabugal. Em termos geomorfológicos constitui o prolongamento para oeste do planalto de Castela-a-Velha, também designado de Meseta. As classes de altitude preponderantes são as compreendidas entre os 700 e os $900 \mathrm{~m}$, enquanto os declives predominantes se encontram abaixo dos $8 \%$, ocupando os inferiores a $2 \%$ uma vasta extensão do território, sobretudo a Este do Rio Côa onde a platitude é mais evidente (Nunes, 2007).

Em termos biogeográficos, integra-se no Superdistrito Altibeirense, onde predominam de forma quase exclusiva as rochas graníticas e onde o clima apresenta características mediterrâneas sub-húmidas. Os bosques climatófilos deste Superdistrito enquadram-se no Genisto falcatae-Quercetum pyrenaicae sendo as suas etapas de substituição mais evidentes os giestais do Lavandulo sampaioanae-Cytisetum multiflori e os urzais do Halimietum alyssoido-ocymoidis e do Genistello tridentatae-Ericetum aragonensis (Costa et al., 1998).

A unidade de paisagem em estudo pode ser enquadrada no conceito de "sistemas agrícolas de elevado valor natural" (High Nature Value Farmland em inglês). Este conceito foi introduzido nos anos 90 e descreve atividades e superfícies agrícolas que, devido às suas características, é expectável suportarem elevados níveis de biodiversidade ou espécies e habitats com preocupaçôes de conservação (Baldock et al., 1993; Beaufoy et al., 1994; Bignal and McCracken, 2000).

\footnotetext{
${ }^{1}$ Não se analisou esta unidade de paisagem pela parca expressão geográfica que assume no município do Sabugal.
} 
Com efeito, os Sistemas Agrícolas de Alto Valor Natural (SAAVN) devem contemplar, em simultâneo, baixa intensidade de produção, baixa utilização de fatores de produção (inputs), presença de vegetação seminatural e elevada diversidade de cobertura do solo (figura 5).

Assim, as características chave dos sistemas de Alto Valor Natural, já identificadas em estudos anteriores, são, de acordo com o GPP (2013), as seguintes:

i) Agricultura de baixa densidade, a qual se caracteriza pela parca utilização de maquinaria, fertilizantes e pesticidas e/ou a presença de baixa densidade de animais de pastoreio.

ii) Presença de vegetação seminatural onde os pastos não melhorados e forragens tradicionais são significativamente mais elevadas face a exploraçóes com uma gestão intensiva. Acresce a presença de outros elementos tais como árvores maduras, matas, pousios, rochas ou habitats lineares como as margens dos campos e sebes, os quais têm um efeito positivo nos nichos ecológicos que possam coexistir em simultâneo com as atividades agrícolas;

iii) Diversidade da cobertura do solo, a biodiversidade é significativamente mais elevada quando existem zonas de mosaico, incluindo culturas extensivas, pousios, vegetação seminatural e características naturais. Os habitats dos mosaicos agrícolas são constituídos por diferentes utilizações do solo, incluindo parcelas de exploraçóes com diferentes culturas, zonas de pastagem, pomares, áreas de mata e bosque. Estas características criam uma extensa variedade de habitats e fontes alimentares para a fauna e, consequentemente, suportam uma muito maior ecologia complexa do que as simples exploraçóes intensivas. 


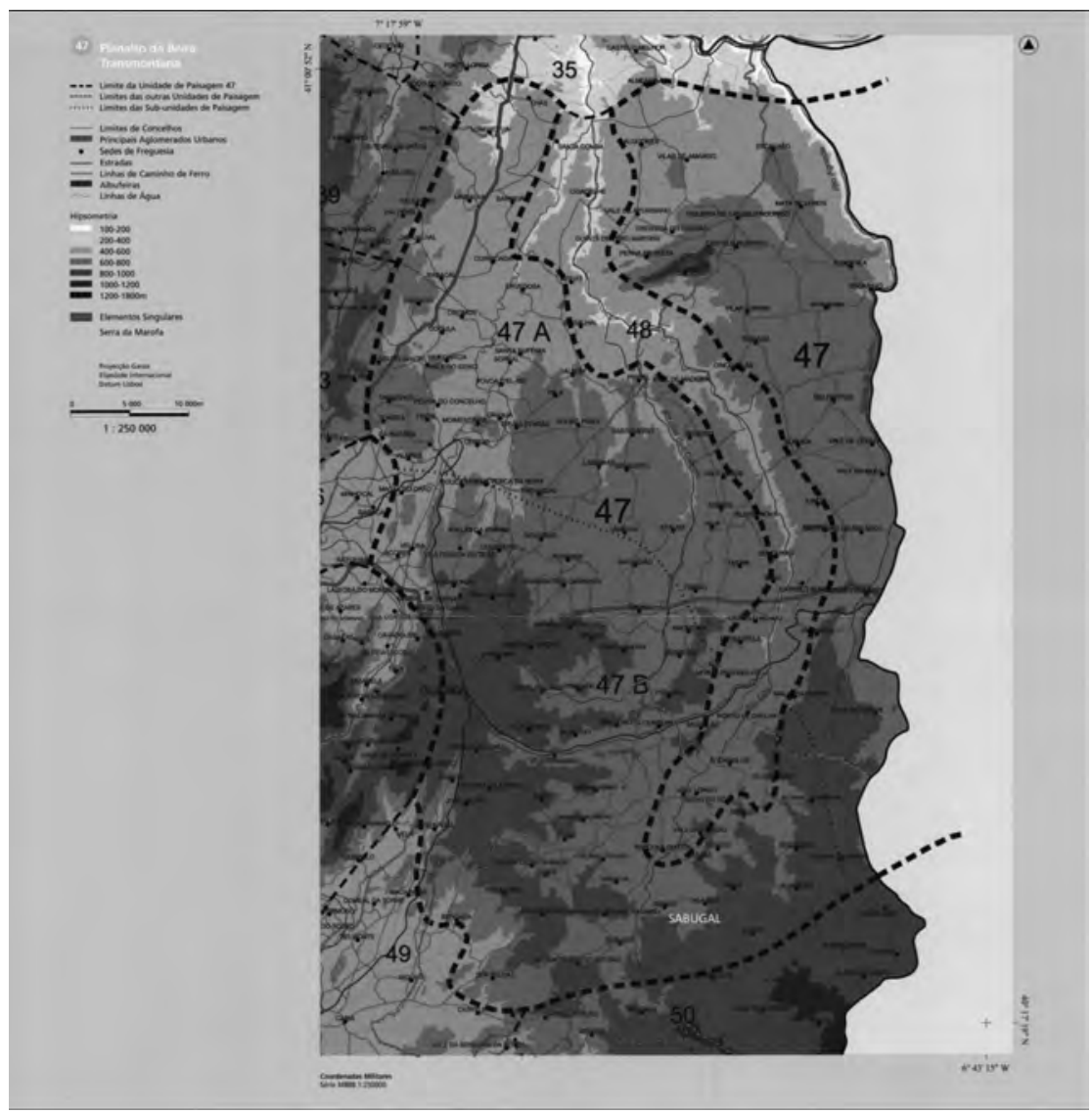

Figura 4

Unidades de paisagem no município do Sabugal (adaptado de Contributos para a Identificação e Caracterização da Paisagem em Portugal Continental

Fonte: http://biblioteca.fa.ulisboa.pt/index.php/42-livros/258-contributos-para-a-identificacao-e-caracterizacao-da-paisagem-em-portugal-continental 


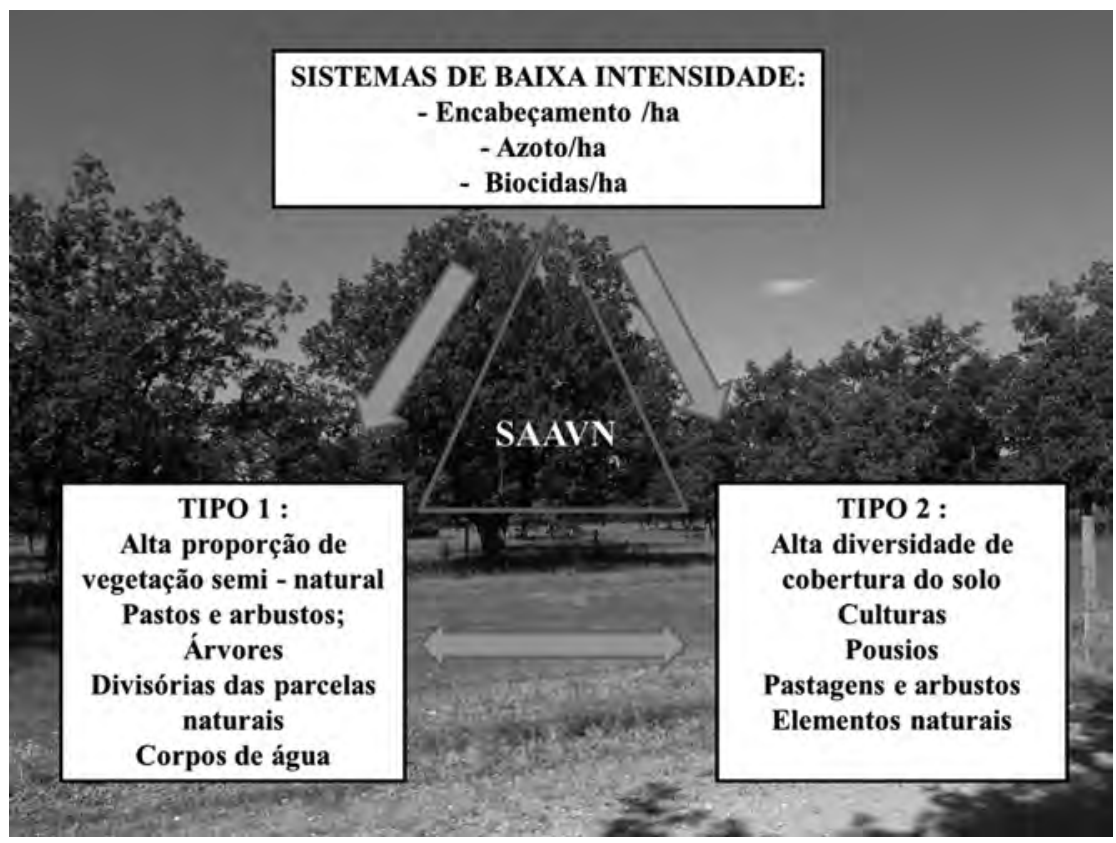

Figura 5

As três características chave dos Sistemas Agrícolas de Alto Valor Natural (SAAVN)

Fonte: (http://www.gpp.pt/estatistica/Indicadores_aa/Docs/Fichas/HNV_ PRRN.pdf)

No caso particular do Planalto da Beira Transmontana, os sistemas agrícolas com maior valor de conservação de biodiversidade, e também mais representativos em toda a Europa, são os sistemas de pastoreio extensivo, baseados em culturas forrageiras naturais, pastoreadas ou cortadas para feno, aliados a uma baixa densidade de encabeçamento, baixa produtividade e baixa intensidade nos consumos de fertilizantes, com uma elevada incorporação de pousios nos sistemas de rotação de culturas, e com a presença de vegetação autóctone em recuperação (ex. Quercus pyrenaica). Para a área em estudo o encabeçamento (n. ${ }^{\circ}$ de cabeças de gado graúdo/ha) não deverá ultrapassar os 0,6 (GPP, 2013). 
Estes ecossistemas agrícolas providenciam importantes serviços de ecossistemas, tanto de produção, com benefícios diretos para o Homem (produção de alimento), mas também outros de suporte e regulação (ligados à conservação do solo, sequestro de carbono, preservação de habitat, refúgio, polinização, etc.), assim como culturais (lazer, recreio, educação, etc.), cujos benefícios ainda não são contabilizados em termos de mercado ou económicos em geral.

\section{Serra da Malcata}

As características físicas e biológicas da serra da Malcata conferem-lhe uma enorme importância potencial no fornecimento de um diverso leque de serviços dos ecossistemas. Com uma altitude a ultrapassar os $1070 \mathrm{~m}$, uma litologia dominada pelo complexo xisto-grauváquico e com valores de precipitação bastante mais elevados (a ultrapassar, em média, os $1300 \mathrm{~mm}$ anuais de acordo com os valores recolhidos na estação de Vale de Espinho), face à área envolvente, conferem a este relevo saliente relevância em termos de disponibilidade de água, de biodiversidade, de refúgio, e, também, em termos culturais, justificação para a sua classificação como área protegida (Reserva Natural da Serra da Malcata, em 1981) e a sua integração na Rede Natura 2000. Por conseguinte, a serra da Malcata é, por vezes, catalogada como um dos últimos refúgios naturais do território português, devido aos valores botânicos e faunísticos e por constituir uma das áreas de eleição para a preservação do lince ibérico (Lynx pardinus), classificado em perigo de extinção.

A parte norte, integrada no município do Sabugal, com altitude a oscilar entre os 800 e os $1000 \mathrm{~m}$, declives menos acentuados, com cambissolos húmicos e dístricos e ombroclima húmido a hiper-húmido, é dominada por bosques de Quercus pyrenaica, normalmente abertos devido a perturbaçóes antrópicas e também devido ao fogo, apresenta ainda um cortejo florístico muito rico onde se destaca Sorbus latifolia (mostageiro), Genista falcata, Aquilegia vulgaris (erva pombinha), Polygonatum odoratum (selo de Salomáo), Cruciata glabra, Luzula campestris, Prunella grandiflora, Primula vulgaris (rosas de Páscoa), 
Anthoxanthum odoratum (feno de cheiro) e Viola riviniana, sendo algumas delas endemismos ibéricos.

Segundo o Plano de Ordenamento da Reserva Natural, distinguem-se as seguintes tipologias, ordenadas por ordem decrescente do nível de proteção: (i) Áreas de proteção total (visam a manutenção dos processos naturais em estado tendencialmente imperturbável e a preservação de exemplos ecologicamente representativos num estado dinâmico e evolutivo); (ii) Áreas de proteção parcial (contêm valores naturais e paisagísticos com significado e importância relevante ou excecional do ponto de vista da conservação da natureza, bem como sensibilidade ecológica moderada); (iii) Áreas de proteçấo complementar (ainda áreas rurais, onde é praticada agricultura permanente ou temporária, silvicultura, silvo-pastorícia e pastorícia, em proporçôes e intensidade, de que resultam habitats importantes no seu conjunto para a conservaçâo da natureza e onde a estrutura e as componentes da paisagem devem ser mantidas ou valorizadas); (iv) Áreas de intervençâo específica (áreas com elevado interesse para a conservação da diversidade biológica, que, devido a fortes pressōes antrópicas a que foram sujeitas, necessitam de medidas de proteçấo, recuperaçáo ou reconversão).

Com efeito, as montanhas e outras áreas serranas, pelo seu elevado valor ecológico, pelo papel que desempenham na preservação da biodiversidade, congregam serviços variados que vão desde a proteçáo do solo, a qualidade da água, a regularização do ciclo hidrológico, contribuição para o sequestro de carbono, até aos serviços de recreio (Zhang et al., 2007). Constituem, igualmente, espaços privilegiados para determinados habitats, cumprindo funçôes de refúgio, nidificação, polinização, entre outros.

A produção de energia, a partir do vento e da água (barragem do Sabugal e transvase para a barragem do Meimão) são igualmente serviços dos ecossistemas (Sepp, 2007) presentes neste território. 


\section{Vale do Côa}

Apesar de não poder ser considerada uma unidade de paisagem principal, por constituir mais um corredor, de acordo com Forman e Godron (1986), os cursos de água, respetivas comunidades ripícolas e habitats envolventes, moldam e estruturam a paisagem, assumindo em simultâneo cinco tipos de funçôes (Forman, 1995): Habitat, Conduta, Filtro, Fonte e Sumidouro.

Com efeito, esta unidade "Vale do Côa" aparece individualizada relativamente à envolvente (Planalto da Beira Transmontana) apenas a jusante da aldeia de Rapoula do Côa, quando o encaixe do vale começa a diferenciar-se do planalto encaixante (Cancela d'Abreu et al. (2004). No essencial, caracteriza-se por vertentes abruptas, declives acentuados, solos pobres e um clima de fortes contrastes térmicos e reduzidos quantitativos de precipitação.

O Côa, que nasce na Serra das Mesas, constitui, como todos os ecossistemas aquáticos e terrestres associados, um sistema complexo interativo, compostos por água, solo, fauna e flora (MAOTDR, 2009), prestando múltiplas funções e serviços, proporcionadas por estes componentes.

Com efeito, estes corredores, associados a diferentes tipologias de linhas de água, desempenham um papel importante no controlo do escoamento hídrico e dos sedimentos, interceçáo de nutrientes e reduçáo de processos erosivos, diversidade de espécies florísticas e faunísticas e valorização estética da paisagem. De acordo com Saraiva (1999), os sistemas fluviais constituem sistemas abertos - formados por todos os elementos componentes dos processos de erosão e deposição na paisagem fluvial e que devem ser considerados como um todo (Schumm, 1977; Saraiva, 1999) - que desempenham várias funçôes, entre as quais se destaca (Cheias, 1988; Saraiva, 1999): (i) a funçáo hidráulica, de drenagem e escoamento das águas da bacia, através de processos de escoamento e infiltração; (ii) a função biofísica, como suporte das biocenoses aquáticas e ribeirinhas e estabilização das margens; (iii) a funçâo económica, através da utilizaçáo dos seus recursos pelos diversos agentes económico-sociais (água, pesca); (iv) função cultural, estética e recreativa, através da sua utilização como espaço de lazer e recreio. 


\section{Consideraçóes finais}

As mudanças no uso do solo decorrentes do abandono da atividade agrícola constituem, sem dúvida, o mais importante promotor das alteraçóes dos serviços dos ecossistemas nas áreas rurais do interior do país. Assim, com a ruptura da função clássica de produção, agrícola e florestal, as paisagens rurais transformaram-se progressivamente em espaços abertos de consumo, em que o padráo de uso do solo deixa de ser dominado pela agricultura.

Sob os atuais paradigmas económicos, alguns serviços dos ecossistemas, de regulação, de suporte e culturais, à exceção da recreação e turismo, não têm um valor económico e não são remunerados pelo mercado. A produção de água e o sequestro de carbono constituem, na atualidade, dois serviços dos ecossistemas relevantes socialmente, mas ainda sem valoração económica.

Nos territórios de fronteira, à semelhança de tantos outros do interior Centro e Norte e Sul do país, a manutenção dos agro-ecossistemas tradicionais, ou melhor a sua adaptaçáo aos novos tempos, pode mesmo ser a chave para termos, ao mesmo tempo, mais serviços de aprovisionamento e mais serviços de regulação e culturais. De facto, a grande inovação introduzida pelo conceito de serviços de ecossistemas é a sua capacidade em integrar a dimensão ecológica e a dimensão socioeconómica dos ecossistemas. A integração destes dois domínios é crucial para a sustentabilidade dos ecossistemas/ paisagens. Emergem, todavia, questôes pertinentes e de difícil resolução, entre as quais se destacam: (i) Como reconhecer os serviços relevantes para a área? (ii) Como avaliar a sua disponibilidade e o seu valor económico? (iii) Como promover a sua valorização em favor dos agentes e populaçôes locais? Com efeito, a crescente relevância destas funçôes num quadro de sustentabilidade pode criar importantes oportunidades sociais e económicas para o desenvolvimento rural, mas, ao mesmo tempo, coloca questôes que se prendem com a aprendizagem de novos conceitos e formas de gestấo, em relação aos quais é necessário um investimento considerável, tanto em termos técnicos e científicos como em termos operacionais, por parte dos atores que as póem em prática no terreno. 
Todavia, estas questôes revelam evidentes preocupaçôes e constrangimentos se tivermos em consideração as condiçôes socioeconómicas da área de estudo, a qual se caracteriza por baixas densidades populacionais, elevados índices de envelhecimento e taxas de analfabetismo ainda muito significativas. De facto, manter os ecossistemas naturais, seminaturais e cultivados em bom estado só será possível por intermédio de uma estratégia que mobilize os decisores políticos e económicos, bem como a população em geral, a vários níveis: local, regional e global.

Com efeito, uma paisagem diversa oferece um leque variado de opçóes de gestáo, disponibiliza um maior número de serviços e produtos e, possivelmente, é mais resiliente perante perturbaçóes extremas do que as paisagens simplificadas pelo abandono agrícola.

\section{Referências}

Almeida, J. A. G. (2013). Os serviços dos ecossistemas na valorização dos espaços agrícolas: perspetivas gerais e aplicação a um território rural de montanha. Mestrado em Ciências e Tecnologia do Ambiente, FCUP, 115 p.

Baldock, D. (1993). Nature Conservation and New Directions in the EC Common Agricultural Policy. Institute for European Environmental Policy.

Barbancho, A. C. \& Tejeda, E. M. (2006). Evolución de las aportaciones hídricas en una cuenca de montaña del Sistema Central: cabecera fluvial del río Tormes (1941-2004). Cuadernos de Investigación Geográfica, 32, pp. 7-28.

Beaufoy, G.; Baldock, D. \& Clark, J., (1994). The Nature of Farming: Low Intensity Farming Systems in Nine European Countries. IEEE, London, United Kingdom.

Beguería, S.; López-Moreno, J.; Lorente, A.; Seeger, M. \& García-Ruiz, J. M. (2003) - Assesssing the effect of climate oscilations and land-uses changes on streamflow in the Central Spanish Pyrenees. Ambio, 32 (4), pp. 283-286.

Belmonte Serrato, F.; Romero Díaz, A.; López Bermúdez, F. \& Hernández Laguna E. (1999). Óptimo de la cobertura vegetal en relación a las pérdidas de suelo por erosión hídrica y las pérdidas de lluvia por intercepción. Papeles de Geografía, 30, pp. 5-15.

Bignal, E. M. \& McCracken, D. I. (2000). The nature conservation value of European traditional farming systems. Environmental Reviews, 8(3), pp. 149-171.

Bosch, J. M. \& Hewlett, J. D (1982). A review of catchment experiments to determinate the effect of vegetation changes on water yield and evapotranspiration”. Journal of Hydrology, 5, pp. 3-23.

Burgi, M.; Silbernagel, J.; Wu, J.; Kienast, F. (2015). Linking ecosystem services with landscape history. Landscape Ecology, 3, pp. 11-20. 
Cancela d'Abreu, A.; Pinto Correia, T. \& Oliveira, R. (Coord.) (2004). Contributos para a Identificação e Caracterização da Paisagem em Portugal Continental DGOTDU, Portugal.

Cheias, G. T. (1988). Recomendaçóes para a Protecção e Estabilizaçâo de Cursos de Água. Lisboa: DGRN, SEARN, MPAT.

Costa, J. C.; Aguiar, C.; Capelo, J. H.; Lousâ, M. \& Neto, C. (1998). Biogeografia de Portugal Continental. Quercetea, 0, pp. 5-57.

Costanza, R.; d'Arge, R.; De Groot, R. S.; Farber, S.; Grasso, M.; Hannon, B.; Limburg, K.; Naeem, S.; O’Neill, R. V.; Paruel, J.; Raskin, R. G.; Sutton, P. \& Van den Belt, M. (1997) - The value of the world's ecosystem service and natural capital. Nature, 38, pp. 253-260.

Cumming, G. S.; Olsson, P.; Chapin, F. S. \& Holling, C. S. (2012). Resilience, experimentation, and scale mismatches in social-ecological landscapes. Landscape Ecology, 28(6), pp. 1139-1150.

Dallimer, M.; Davies, Z. G.; Diaz-Porras, D. F.; Irvine, K. N.; Maltby, L.; Warren, P. H.; Armsworth, P. R.; Gaston, K. J. ( 2015). Historical influences on the current provision of multiple ecosystem services. Global Environmental Change, 3, pp. 307-317.

Dearing, J. A.; Yang, X. D.; Dong, X. H.; Zhang, E. L.; Chen, X.; Langdon, P. G.; Zhang, K.; Zhang, W. G. \& Dawson, T. P. (2012). Extending the timescale and range of ecosystem services through paleoenvironmental analyses, exemplified in the lower Yangtze basin. Proc. Natl. Acad. Sci. U. S. A., 109, E1111-E1120.

DGT (Direçấo Geral do Território) (2015). Carta das Unidades de Paisagem em Portugal Continental (CUP). (acedido a 01 de março de 2015, em http://www.dgterritorio.pt/sistemas_de_informacao/ snit/cup/).

Forman, R. T. T. \& Godron, M. (1986). Landscape ecology. New York: John Wiley \& Sons, 620 p.

Forman, R.T.T. (1995). Some general principles of landscape and regional ecology. Landscape Ecology, 10(3), pp.133-142.

Gallart, F. \& Llorens, P. (2001). Water resources and environmental changes in Spain. A key issue for sustainable integrated catchment management. Cuadernos de Investigación Geográfica, 27, pp. 7-16.

García-Ruiz, J. M. (2010). The effects of land uses on soil erosion in Spain: a review. Catena, 81, pp. 1-11.

GPP (2013). Ficha - Área agricola e florestal de elevado valor natural. (http://www.gpp.pt/estatistica/ Indicadores_aa/Docs/Fichas/HNV_PRRN.pdf), consultado em 15/3/2016.

Groot, R. S.; Alkemade, R.; Braat, L.; Hein, L. \& Willemen, L. (2010). Challenges in integrating the concept of ecosystem services and values in landscape planning, management and decision making. Ecological Complexity, 7(3), pp. 260-272.

Groot, R. S.; Wilson, M. \& Boumans, R. (2002). A typology for the description, classification and valuation of ecosystem functions, goods and services. Ecological Economics, 41(3), pp. 393-408.

Holland, R. A.; Eigenbrod, F.; Armsworth, P. R.; Anderson, B. J.; Thomas, C. D.; Gaston, K. J. (2011). The influence of temporal variation on relationships between ecosystem services. Biodivers. Conserv, 20, pp. 3285-3294.

Jiang, M.; Bullock, J. M. \& Hooftman, D. A. P. (2013). Mapping ecosystem service and biodiversity changes over 70 years in a rural English county. J. Appl. Ecol., 50, pp. 841-850.

Lautenbach, S.; Kugel, C.; Lausch, A. \& Seppelt, R. (2011). Analysis of historic changes in regional ecosystemserviceprovisioningusing landusedata. Ecol.Indic.,11, pp. 676-687. 
Madureira, L.; Magalhães, P.; Gabriel Silva, P.; Marinho, C. \& Oliveira, R. (2013). Economia dos Serviços de Ecossistema - Um guia para conhecer e valorizar serviços de agroecossistemas em áreas protegidas de montanha (I.). Quercus - Associaçáo Nacional de Conservação da Natureza.

MAOTDR (Ministério do Ambiente, do Ordenamento do Território e do Desenvolvimento Regional) (2009). Articulaçâo entre a Gestão da Água e a Conservação da Natureza e da Biodiversidade, 150p. (https://repositorium.sdum.uminho.pt/bitstream/1822/36599/1/ document_2755_1.pd)

Millennium Ecosystem Assessment (MEA) (2005). Ecosystems and Human Well Being: Synthesis. Washington DC: Island Press.

Moreira, F.; Viedma, O.; Arianoutsou, M.; Curt, T.; Koutsias, N.; Rigolot, F.; Barbati, A.; Corona, P.; Vaz, P.; Xanthopoulos, G.; Mouillot, F. \& Bilgili, E. (2011). Landscape - wildfire interactions in southern Europe: Implications for landscape management. J. Environ. Manage., 92(1), pp. 2389-2402.

Musacchio, L. R. (2009). The scientific basis for the design of landscape sustainability: a conceptual framework for translational landscape research and practice of designed landscapes and the six Es of landscape sustainability. Landscape Ecology, 24(8), pp. 993-1013.

Nunes, A. \& Jacinto, R. (2011). Interioridade, despovoamento e coesão do território: Sabugal e as fronteiras do desenvolvimento raiano. Iberografias 17, pp. 69-100, Ed. Centro de Estudos Ibéricos, Guarda.

Nunes, A. (2008). Abandono do espaço agrícola na "Beira Transmontana. Iberografias 13, Ed. Campo das Letras SA, $430 \mathrm{p}$.

Nunes, A.; Figueiredo, A. \& Almeida, A. C. (2012). The effects of farmland abandonment and plant succession on soil properties and erosion processes: a study case in central of Portugal. Revista de Geografia e Ordenamento do Território, 2, pp. 165-190. Centro de Estudos de Geografia e Ordenamento do Território.

Nunes, A.; Lourenço, L.; Bento-Gonçalves, A. \& Vieira, A. (2013), Três décadas de incêndios florestais em Portugal: incidência espacial e principais fatores responsáveis. Cadernos de Geografia, 32, pp. 133-143, Faculdade de Letras, Coimbra.

Pardini, G.; Gispert, M. \& Dunjó, G. (2002) - Runoff erosion and nutrient depletion in five Mediterranean soils of NE Spain under different land use. The Scien. of the Total Environ., 309, pp. 213-224.

Pereira, H. M.; Domingos, T.; Vicente, L. \& Proença, V. (Editores) (2009). Ecossistemas e Bem-Estar Humano: Avaliação para Portugal do Millennium Ecosystem Assessment. Lisboa: Escolar Editora.

Pinheiro, H.; Castro, J. P. \& Azevedo, J. (2014). Alteraçóes na paisagem e sequestro de carbono na freguesia de Deilão, nordeste de Portugal. Revista Árvore, 38(1), pp. 41-52.

Pinto-Correia, T. (2007). Multifuncionalidade da paisagem rural: novos desafios à sua análise. Inforgeo, 20/21, pp. 67-71.

Saraiva, M. G. (1999). O Rio como Paisagem. Lisboa: Fundação Calouste Gulbenkian e Fundação para a Ciência e Tecnologia.

Schumm, S. A. (1977). The Fluvial System. New York: John Wiley\&Sons.

Sepp, K. (2002). Landscape Functions and Ecosystem Services. In J. F. Hart, The Rural Landscape. Hardback, pp. 39-52. 
Sil, A. F. P. C. (2014). Alterações da paisagem e serviços de ecossistema: Quantificação e valoração do sequestro de carbono na bacia superior do Rio Sabor. Diss. apresentada à Escola Superior Agrária de Bragança para obtenção do Grau de Mestre em Gestão de Recursos Florestais, 95 p.

TEEB Foundations (2010). The Economics of Ecosystems and Biodiversity: Ecological and Economic Foundations. Earthscan, London and Washington.

Tianhong, L.; Wenkai, L. \& Zhenghan, Q. (2010). Variations in ecosystem service value in response to land use changes in Shenzhen. Ecol. Econ. 69, pp. 1427-1435.

VanShaar, J. R.; Haddeland, I. \& Lettenmaier, P. (2002). Effects of land-cover changes on the hydrological response of interior Columbia River basin forest catchments. Hydrological Processes, 16, pp. 2499-2520.

Wu, J. (2013). Landscape sustainability science: ecosystem services and human well-being in changing landscapes. Landscape Ecology, 28 (6), pp. 999-1023

Zhang, W.; Ricketts, T. H.; Kremen, C.; Carney, K.; Scott, M. \& Swinton, S. M. (2007). Ecosystem services and dis-services to agriculture. Ecological Economics, 64, pp. 253-260.

Zhao, S. Q.; Da, L. J.; Tang, Z. Y.; Fang, H. J.; Song, K. \& Fang, J. Y. (2006). Ecological consequences of rapid urban expansion: Shanghai, China. Front. Ecol. Environ., 4, pp. 341$-346$. 